\title{
Optimization of Operational Parameters in Biogas Plants using the Anaerobic Digestion Model Number 1 (ADM1)
}

\author{
David Wagner*, Wolfgang Schlüter \\ Department of Engineering, Hochschule Ansbach, Residenzstraße 8, 91522 Ansbach, Germany; \\ *david.wagner@hs-ansbach.de
}

SNE 30(1), 2020, 11 - 14, DOI: 10.11128/sne.30.sn.10503 Received: June 10, 2019 (Selected ASIM SST Hamburg 2018

Postconf. Publ.), Accepted: October 10, 2019

SNE - Simulation Notes Europe, ARGESIM Publisher Vienna

ISSN Print 2305-9974, Online 2306-0271, www.sne-journal.org

Abstract. While the main objective in energy production is the reduction of fossil fuels, CO2-production by fossil fuels increased over the last decade. Therefore the need for usage of regenerative energies is obvious. Biogas plants are advantageous because they can be used without spatial limitation and their substrate is abundant ubiquitously as it covers the whole range of produced organic matter from photosynthesis, municipal, industrial and animal waste. Although the need for optimization strategies is given, the fermentation process in biogas plants is complex and therefore traditional optimization approaches are cumbersome and carry the risk of complete plant failure. In this paper the optimization potential of the ADM1, which represents a detailed description of the anaerobic digestion process is analysed and compared to the standard ADM1 setup. Technical parameters like substrate composition and dilution rate are optimized to yield a high methane gas flow. It is shown that the optimization of substrate composition has a direct impact on the maximum applicable dilution rate. It is also shown that the feeding rate can be increased to yield higher productivities with optimized substrate compositions.

\section{Introduction}

In first half year of 2018 renewable energy sources replaced coal as the major energy resource with around 117,8 TWh [1]. From these energies, biomass is, due to its wide abundance, a perfect complement to wind and solar energy. Biomass is a prerequisite for biogas production. The fermentation process needed for biogas production is consisting of a multitude of consecutive steps with several bacterial species involved. The anaerobic digestion can be used to break down any given substrate besides wood. The need for rational optimization is given because the process complexity makes traditional optimizations difficult. Process optimization with the help of experimental design methods would be expensive and time-consuming. Although it is known that high protein amount yields higher theoretical methane production, the additionally produced ammonia is limiting the reaction rate. A condition for the usage of optimization algorithms is a suitable anaerobic digestion model. Many models are available describing the process in differing detail. However, only two of them can be seen as state of the art, the Siegrist model [2] and the anaerobic digestion model No. 1 (ADM1) [3]. Both of them were developed in 2002. Compared to the ADM1 the Siegrist model is smaller, which means lower simulation times at the price of less details. Due to its versatility the ADM1 is used more often. In the case of ADM1, Parker points out, that the validation against different anaerobic digestion scenarios is only a matter of detailed feed characterization [4]. This is also one reason why the acceptance of the model in research is higher than in industry [5]. Further reasons are the complexity of the ODEs and the need for exactly characterizing feedstock as input feed [6]. However, in a recent paper this model is described as the most comprehensive one [7]. The proposed reaction scheme of the sequential steps in the ADM1 is shown in Figure 1.

The fermentation is characterized by the following steps: A - Disintegration, B - Hydrolysis, C - Acidogenesis, D - Acetogenesis, E - Methanogenesis. While other models only include the fermentation process the 
ADM1 also considers disintegration and mass-transfer as well as cell death, which also contributes to additional particulate and inert matter (not shown in Figure 1). Therefore the strength of the model is the detailed description of underlying phenomena in the process. Hence the ADM1 is a powerful tool to tune the biogas production by applying optimization strategies. To ensure a broader industrial application of this model, in this paper the optimization potential is analysed and compared to the standard values in the ADM1 by simulation.

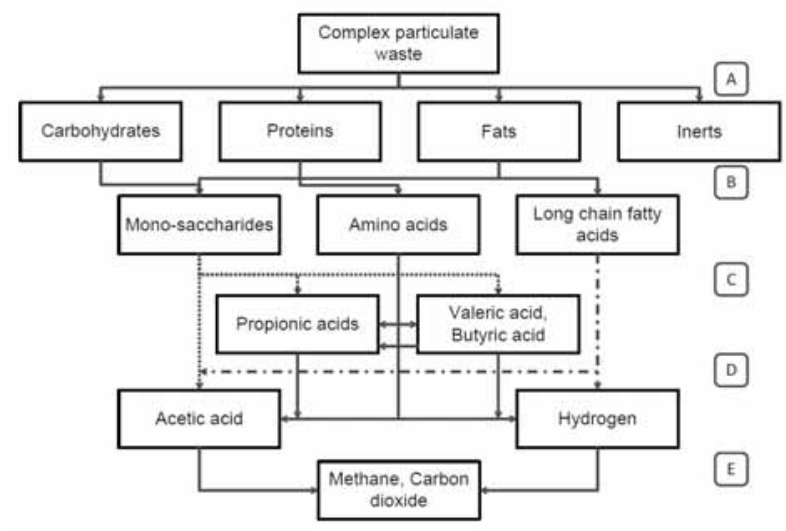

Figure 1: Biogas fermentation process depicted by ADM1 (derived and changed from [3]).

\section{Materials and Methods}

\subsection{ADM1 - Model description}

The model used in this article is an extended variation of the ADM1 of Batstone 2002. The ADM1 originally consists of 32 ordinary differential equations, while the one used in this work includes 39 state variables. Compared to the original model, equations for lactate and calcium are added. Lactate is one of the fatty acids produced in the process, while calcium is used to describe precipitation, which was not included in former models. The model itself is highly nonlinear and includes all steps shown in Figure 1. Due to the complexity, it shows some numerical inconsistencies in specific ranges. It includes physicochemical processes like gas-liquid and liquid-liquid transfer as well as disintegration steps. The hydrolysis step is divided into carbohydrates, lipids and proteins which are all first order reactions with different rate parameters. Starting parameters are the standard values described in Batstone 2002 [3] with the initial composition of particulate matter as shown in Table 1.

\begin{tabular}{llll}
\hline Carbohydrate & Fat & Protein & Inert \\
\hline Standard $20 \%$ & $25 \%$ & $25 \%$ & $30 \%$ \\
\hline
\end{tabular}

Table 1: Composition of the standard substrate.

\subsection{Simulation and Optimization}

The initial values for the optimization approach are taken from the standard substrate in Table 1 and additional parameters can be found in [3]. Simulations are done using the ode15s-solver in Matlab 9.2. If not stated otherwise the optimization is done with the tool fmincon from the Matlab Optimization Toolbox. The solver is gradient-based, fast and suited for large problems with certain constraints. A scheme of the optimization procedure is shown in Figure 2. The objective function is always the mean of maximum steady state gas flow of methane (qCH4). The optimized variables are the substrate composition (containing carbohydrates, proteins, fat and inert material) and the applied dilution rate. This leads to a five dimensional optimization problem with the additional constraint that the sum of substrate components is $100 \%$.

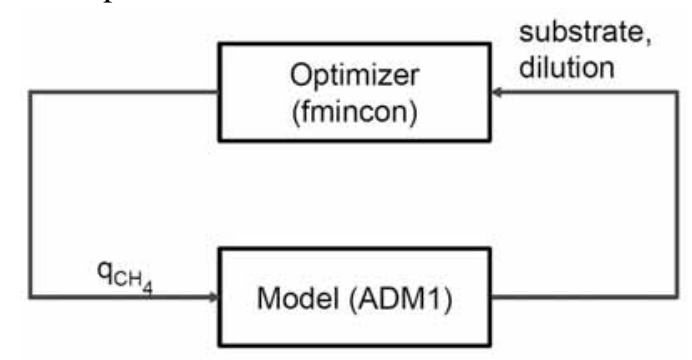

Figure 2: Scheme for optimization with fmincon.

\section{Results and Discussion}

Due to the diversity in the steps leading to methane the possibilities to optimize the process are manifold. From the available technical parameters the most important one is the dilution- or loading-rate which is directly depending on the substrate composition. Additional parameters are the initial $\mathrm{pH}$-value and the temperature. Nevertheless various inhibitory effects hinder the prediction of optimal operation points. While high protein content is favored for methane production, the ammonia originating from proteins can result in process failure [8]. The high ammonia content is especially affecting methanogenic bacteria [9] in consequence VFAs (volatile fatty acids) are accumulated and the $\mathrm{pH}$ drop leads to declining ammonia concentrations. 
Besides the aforementioned substrate, the temperature plays a main role in all (bio-) chemical reactions and is therefore a valuable optimization parameter. However $\mathrm{pH}$ and temperature are not addressed in this study because in the ADM1 the temperature effects are described by the Arrhenius equation only. This makes a detailed analysis of the temperature effects impossible. Additionally it can be concluded that the initial $\mathrm{pH}$ value has only a minor influence. While the other factors are influencing the complete time course of the process, the $\mathrm{pH}$ is changing rapidly due to the reactions in the reactor and reaches equilibrium conditions very fast. Substrate composition and dilution rate have to be optimized simultaneously.

\subsection{Substrate composition}

The substrate composition is essential in the biogas production process. It is widely acknowledged in literature that it has a big influence on the methane yield [10]. Carbohydrates are degraded faster than fats and proteins indicating higher space-time yields of methane. However this is only the case if the acetogenic steps are equally fast as the methanogenid steps. Otherwise fast accumulation of VFA results in a $\mathrm{pH}$ drop inhibiting methane production. The optimization process uses the initial parameters of substrate composition which are given in Table 1. The result of this optimization process is shown in Table 2.

\begin{tabular}{lllll}
\hline & Carbohydrate & Fat & Protein & Inert \\
\hline Optimized $0.1 \%$ & $13.8 \%$ & $86.1 \%$ & $0 \%$ \\
\hline
\end{tabular}

Table 2: Composition of optimized substrate.

It is obvious that $0 \%$ of inert material is favoured. As mentioned earlier high protein contents are also desirable.

However the optimization results are astonishing, because the optimized substrate contains nearly no carbohydrates. This fact is explicable by the fast hydrolysis of carbohydrates leading to high VFA content and a massive $\mathrm{pH}$ drop. Another significant fact is the ratio of approximately $6: 1$ between fat and protein in the optimized substrate. This result matches with literature values, shown in Table 3, demonstrating that the methane content in the biogas is increased significantly by such a ratio [10].

\begin{tabular}{lll}
\hline Substrate & Protein/ Fat ratio & Methane content \\
\hline Optimized & 6.2 & $56.8 \%$ \\
\hline Buckwheat & 6.7 & $57.4 \%$ \\
\hline Fodder radish & 5.7 & $55.1 \%$ \\
\hline
\end{tabular}

Table 3: Comparison of the optimized substrate regarding protein/fat ratio with other used substrates [10].

\subsection{Critical dilution rate (feeding rate)}

The dilution rate describes the flow rate of feed in and out of the biogas fermentation tank. Due to its continuous operation the amount of inflow is equivalent to the outflow. The feed usually contains only substrate, while the outflow contains substrate, product and biomass. Therefore biomass productivity and dilution rate are directly proportional up to the critical dilution rate dcrit. The higher the biomass productivity the more methane is produced. Therefore it is critical for process yield. The critical dilution rate defines the point where an increase of inflow leads to wash-out conditions of biomass and a resulting productivity drop. It is obvious that the maximum applicable dilution rate is coupled with the maximum bacterial growth rate. The ADM1 contains seven bacterial species, two of them are producing methane, the first one via the acetoclastic and the second via the hydrogenotrophic pathway (see Figure 1). Complete process failure is only achieved when both of them are washed out, however it is advisable not to interrupt any pathway. With the optimized substrate composition given in Table 2 the nutritional supply is higher and the applicable dilution rate is larger.

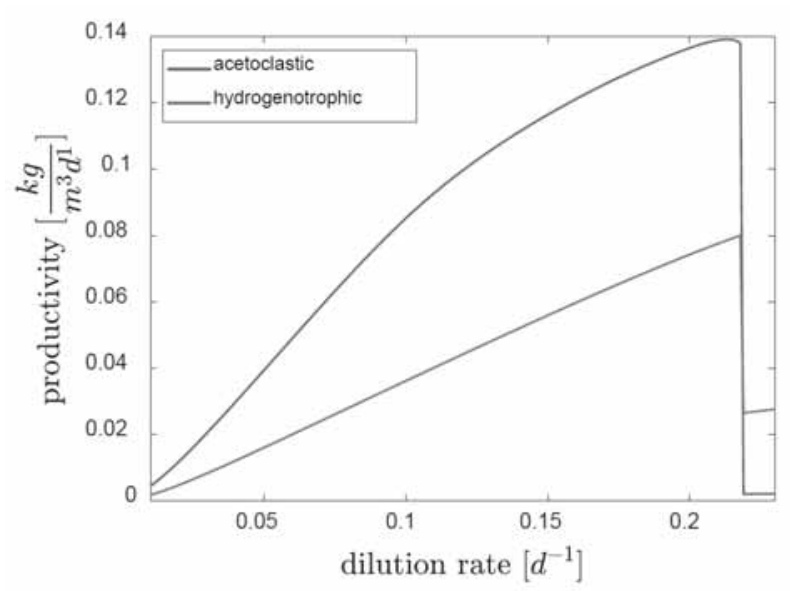

Figure 3: Critical dilution rate for acetoclastic and hydrogeotrophic biomass. 
At a dilution rate of $\sim 0.216 \mathrm{~d}-1$ complete wash-out condition is reached. An operation of $0.2 \mathrm{~d}-1$ should be favoured to maintain high methane yields respecting process fluctuations. In Figure 3 the critcal dilution rate dcrit is indicated by an abrupt productivity drop beyond a dilution rate of $0.216 \mathrm{~d}-1$.

\section{Conclusion \& Outlook}

Many experimental studies are available where different variables are tested to give highest possible methane yields in biogas plant operation. This is done either by using neural networks [11] or by hand, adding supplements to the process [12]. However, detailed experimental investigations of optimization approaches are only feasible in lab scale. The substrate optimization with the help of the ADM1 is not carried out so far. In this article it is shown that it is possible to find optimal operational parameters with the ADM1 model. The steady state methane yield was increased by $\sim 80 \%$ compared to standard values. It has to be mentioned that these are idealized values and it is doubtful that substrates are found fulfilling the optimized nutritional values. However in future applications the ADM1 could be used to define which substrate or substrate mixture should be fed in the biogas reactor. Moreover technical parameters like temperature and $\mathrm{pH}$-value could be incorporated after extending the ADM1. By carrying out these procedures the ADM1 would be a useful tool to increase the biogas production and raise the rentability of biogas plants.

\section{References}

[1] BDEW-Schnellstatistikerhebung Stat. Bundesamt 07/2018

[2] Siegrist H, Vogt D, Garcia-Heras JL, Gujer W. Mathematical model for meso- and thermophilic anaerobic sewage sludge digestion. Environ. Sci. Technol. 2002; 36: 1113-1123.
[3] Batstone DJ, Keller J, Angelidaki I, Kalyuzhnyi SV, Pavlostathis SG, Rozzi A, Sanders WTM, Siegrist H, Vavilin VA. The IWA Anaerobic Digestion Model No. 1 (ADM1). Water Sci. Technol. 2002; 45(10): 65-73.

[4] Parker WJ. Application of the ADM1 model to avanced anaerobic digestion. Biores. Technol. 2005; 96(16): $1832-42$.

[5] Batstone DJ, Keller J. Industrial applications of the IWA anaerobic digestion model No. 1 (ADM1). Water Sci Technol. 2003; 47(12): 199-206.

[6] Batstone DJ, Puyol D, Flores-Alsina X, Rodríguez J. Mathematical modelling of anaerobic digestion processes: applications and future needs. Rev. Environ. Sci. Biotechnol. 2015; 14(4): 595-613.

[7] Poggio D, Walker M, Nimmo W, Ma L, Pourkashnian M. Modelling the anaerobic digestion of solid organic waste - Substrate characterization method for ADM1 using a combined biochemical and kinetic estimation approach. Waste Manage. 2016; 53: 40-54.

[8] Chen Y, Cheng JJ, Creamer KS. Inhibition of anaerobic digestion process: A review. Biores. Technol. 2008; 99(10): 4044-64.

[9] Angelidaki I, Ellegaard L, Ahring BK. A mathematical model for dynamic simulation of anaerobic digestion of complex substrates: focusing on ammonia inhibition. Biotechnol. Bioeng. 1993; 42(2): 159-166.

[10] Herrmann C, Idler C, Heiermann M. Biogas crops grown in energy crop rotations: Linking chemical composition and methane production characteristics. Biores. Technol. 2016; 206: 23-35.

[11] Gueguim Kana EB, Oloke JK, Lateef A, Adesiyan MO. Modeling and optimization of biogas production on saw dust and other co-substrates using Artificial Neural network and Genetic Algorithm. Renew. Energy. 2012; 46: 276-281.

[12] Liu L, Zhang T, Wan H, Chen Y, Wang X, Yang G, Ren G. Anaerobic co-digestion of animal manure and wheat straw for optimized biogas production by the addition of magnetite and zeolite. Energy Converse. Manag. 2015; 97: 132-139. 